\title{
INTERNACIONALIZAÇÃO DA GESTÃO E DA PROPRIEDADE NO SETOR SUCROALCOOLEIRO NACIONAL
}

\author{
SALTORATO, Patrícia ${ }^{1}$ \\ MUNDO NETO, Martin ${ }^{2}$
}

\begin{abstract}
RESUMO: A construção e o desenvolvimento de um mercado de bioenergia fizeram com que o setor sucroalcooleiro brasileiro entrasse na rota dos investimentos bilionários, daqueles ávidos por conquistar seu espaço no promissor negócio do ethanol. A expansão e a reestruturação do setor encerram desafios e oportunidades que, muitas vezes, só as grandes empresas conseguem enfrentar. Isto pode ser visto, hoje, com a baixa dos preços que obriga os menores ou aqueles em dificuldades a venderem seus negócios ou participações nele para os grandes grupos que aproveitam para crescer nesses momentos. Assim muito da reestruturação do setor passa por uma concentração de capital que vem ocorrendo através dos intensos movimentos de fusões, aquisições e instalações greenfield de grupos nacionais e estrangeiros.
\end{abstract}

Palavras-chave: Governança Corporativa. Financeirização. Profissionalização da Gestão do Setor Sucroalcooleiro.

SUMMARY: The construction and development of a bio-energy market has placed the Brazilian sugarcane industry within the eager billionaire investors' route towards conquering some space in the promising ethanol affairs. The industry expansion and re-struturation locks up either challenges also opportunities which many times can only be faced by the huge ones, which survive even when prices drop down as we see today, obliging small producers and the ones facing financial problems to sell their properties or part of them to the biggest groups which grow during these moments. Thus, much of the industry re-strutuaction passes by a capital concentration that is taking place, because of the intense fusions, acquisitions, and greenfield projects from national and foreign investors movements.

Keywords: Corporative Governance. Financialisation. Sugarcane Industry Management Professionalization.

\section{INTRODUÇÃO}

A crescente demanda por biocombustíveis eficientes e menos poluentes catapultou o etanol brasileiro à celebridade corporativa, fazendo convergir a atenção e concentrar o capital de investidores nacionais e estrangeiros no setor sucroalcooleiro, intensificando o movimento de fusões, aquisições, novas instalações e aberturas de capital, acirrando a disputa pelo mercado de bioenergia, destacando o setor sucroalcooleiro nacional no cenário econômico internacional e potencializando as possibilidades de pesquisa científica.

As vantagens competitivas da produção do álcool combustível brasileiro, mundialmente conhecido como ethanol, sobre os EUA, atuais maiores produtores mundiais de álcool (produzido 1 Doutora em Engenharia de Produção-UFSCar, Coordenadora Docente do Curso de Administração de empresas da FFCL/FE, Pesquisadora do Núcleo de Sociologia Econômica e das Finanças do NESEFI-DEP/UFSCar.

2 Doutorando em Engenharia de Produção-UFSCar, Docente do Curso de Administração em Agronegócios da FFCL/FE, Pesquisador do Núcleo de Sociologia Econômica e das Finanças do NESEFI-DEP/UFSCar. 
a partir do milho), saltam aos olhos dos investidores nacionais e estrangeiros: abundância e qualidade da terra, clima favorável sem necessidade de irrigação artificial (na maior parte do território nacional), preço baixo das propriedades (em comparação com o mercado internacional), baixo custo da mão-de-obra e domínio tecnológico, têm atraído um intenso fluxo de capitais para o setor, que nos três primeiros meses de 2007 somou US\$ 6,5 bilhões, segundo o Banco Central. (ZANATTA, 2007)

Boa parte desse montante tem relação com o apetite dos fundos private equity por investimentos (e retornos) imediatos com o ethanol, o que tem sido saciado com participações em negócios, já estabelecidos através dos processos de fusões e/ou aquisições. Porém, a gula é tanta que mesmo diante das dificuldades de se adquirir participações no Estado de São Paulo, dada a alta dos preços das usinas paulistas, os investidores têm partido para projetos greenfield (que começam do zero) no Mato Grosso, Espírito Santo e em Goiás, demonstrando a musculatura do capital estrangeiro. (REGALADO; FAN, 2007)

Os aportes desses fundos private equity e a abertura de capital figuram como as mais atrativas tanto para os investidores como para os industriais do setor, sendo a possibilidade de conjugar ambas, mais atraente ainda. Isso acontece, à medida que, por um lado, o mercado de capitais se apresenta como uma opção de desinvestimento interessante para os fundos private equity após o período de 5 a 7 anos, em média, durante o qual o fundo atua no sentido de criar valor para sua aquisição, através de engenharia financeira, melhorias na gestão, ou ambas, e por outro lado; o mercado de capitais se revela fértil como fonte de financiamento para as empresas do setor após a abertura de seu capital.

A participação desses fundos no setor sucroalcooleiro começou a deslanchar em 2006, com a entrada da Infinity Bio-Energy no país, que através dos fundos Evergreen e Kidd and Company deu início à sua escalada adquirindo 5 usinas em Minas Gerais, Espírito Santo e Mato Grosso do Sul (SCARAMUZZO a, 2007). Mais recentemente (maio/2007) os fundos de private equity Carlyle e Riverstone, Global Foods, Governança e Gestão e Gávea participaram do processo de fusão entre as usinas Santa Eliza e Vale do Rosário. A abertura de capital, sonho de muitas, negócio para poucas (e gigantes) do setor, foi primeiro alcançado pelo Grupo Cosan, em 2005 e seguida pelos grupos São Martinho (fev/2007), Nova América (mai/2007) e Guarani (set/2007).

Segundo André Castello Branco, diretor da KPMG, consultoria especializada em processos de fusões e aquisições, estas operações no sucroalcooleiro já somam pelo menos 12 este ano, ante nove em 2006 (BALTHAZAR, 2007) e, segundo Marcus Regueira, presidente da Associação Brasileira de Private Equity e Venture Capital (ABVCAP), existem várias negociações sigilosas em andamento no setor sucroalcooleiro envolvendo a participação de fundos private equity, detentores de US\$ 4 bilhões, dos quais boa parte, destinados aos mercados de açúcar e álcool brasileiros (SCARAMUZZO; VALENTI, 2007).

Uma importante dimensão a ser considerada nesse processo é a relação entre o movimento de fusões e aquisições e o investimento estrangeiro. Os investimentos estrangeiros 
em usinas de álcool no Brasil poderão ultrapassar US\$ 9 bilhões nos próximos anos, se forem concretizados os projetos de empresas, que fizeram consultas junto à Dedini Indústrias de Base. Segundo José Luiz Olivério, vice-presidente de operações da Dedini, além dos 88 projetos em fase de instalação por grupos nacionais, existe outros 189 em estudos, dos quais pelo menos $50 \%$ são de grupos estrangeiros. De acordo com dados da União da Indústria de Cana-deAçúcar (Unica), existem hoje no Brasil 357 usinas em operação. A estimativa do governo é que tais usinas processarão na safra 2007/08 entre 475 milhões e 480 milhões de toneladas de canade-açúcar, do qual 6\% será processada por estrangeiros, e de acordo com Antônio de Pádua Rodrigues, diretor técnico da Unica, até 2010, os grupos estrangeiros deverão responder por $10 \%$ da produção do setor caso as previsões da demanda internacional e os investimentos em infra-estrutura nacional (alcoolduto, portos, estradas) se efetivem. (SCARAMUZZO b, 2007)

A revolução mundial na área de energia colocou o Brasil no centro de um processo de investimentos internacionais bilionários e disputas acirradas pelos melhores negócios. A atuação dos fundos PE, em meio aos movimentos de fusões e aquisições, geralmente, intermediados por consultorias especializadas, que culminam na abertura de capital das empresas, realimentamse forjando o novo ambiente institucional do setor; agora co-habitado por atores nacionais e estrangeiros do espaço financeiro atuando segundo um novo contorno das linhas de poder no setor, e adotando a governança corporativa, legitimam o mercado de capitais e o modelo de gestão preconizado por ele, atraindo novos investidores.

\section{OBJETIVO}

Utilizando-se dos conceitos da análise institucional das organizações e da gestão de operações, pretende-se desenvolver um estudo institucionalista multidisciplinar que aproveite as contribuições da economia e da sociologia para analisar a dinâmica das estratégias de empresas que operam simultaneamente no seu espaço original (setor sucroalcooleiro) e no espaço financeiro (mercado financeiro, em particular, nas bolsas de valores do país e do exterior). Pretendem-se identificar as transformações no ambiente interno desses grupos empresariais analisando como o perfil, as decisões e justificativas dos seus principais representantes (diretores, conselheiros, consultores) refletem as estratégias que operam em cada um deles. Interessa-nos, também, identificar quais os principais instrumentos de gestão que foram recentemente adotados e em que medida esses instrumentos reorientaram as operações produtivas.

\section{JUSTIFICATIVA}

Um estudo conduzido pela Value Partners Brasil e FGV-EAESP (2006) mostra que o envolvimento dos gestores de fundos private equity se faz mais direto e intenso do que se imaginava, sendo a revisão de metas e a troca de executivos as principais (e iniciais) providências tomadas pelos gestores de fundos de private equity nos primeiros cem dias à frente do 
monitoramento das empresas de seu portfólio visando à garantia dos altos retornos aos altíssimos investimentos. $\mathrm{O}$ monitoramento se intensifica à medida que a empresa caminha em direção à abertura de capital em bolsa de valores com a adoção de ferramentas de gestão "sintonizadas" com a lógica de mercado, tipicamente técnicas de gestão de cunho "individualizante" capazes de rastrear dentro de um sistema produtivo, a contribuição individual de cada recurso (humano ou não), subsidiando as decisões de (des)investimentos. Após a abertura de capital, o modelo a ser seguido passa a ser o receituário neoliberal da governança corporativa, que segundo analistas do setor, condiciona o aporte dos fundos.

Mais que meras estratégias de financiamento e gestão, os movimentos deflagrados por estes novos players colaboram com a instauração de uma nova ordem cognitiva de percepção sobre as empresas estendendo a lógica liberal às empresas, transformando suas estruturas de governança, até então centradas na liderança e experiência dos gerentes, em relações cada vez mais parecidas com as relações de mercado, onde o imperativo da liquidez orienta as decisões dos conselhos administrativos, agora, povoados por atores dos espaços financeiros (shareholders), cuja visão de mundo impõe uma ordem concorrente aos atores dos espaços industriais (stakehoders) sobre o modo legítimo de ver, entender e conduzir esses negócios. Enquanto para os primeiros, a empresa não passa de um feixe de contratos, para os atores do espaço agrário-industrial do setor sucroalcooleiro nacional, onde seus negócios confundem com seus antepassados, simbolizam um pouco mais que isso.

\section{REFERENCIAL TEÓRICO}

Em função do contexto brevemente exposto, o enfoque da Sociologia das Finanças se apresenta bastante pertinente para uma análise do setor, pois, segundo Grün (2004), esse ramo da Sociologia Econômica se debruça sobre as questões financeiras e passou a ocupar um respeitável subespaço dentro das ciências sociais, amparado nos trabalhos de Karl Polanyi, [2001(1944)], quando da idéia da construção social dos mercados, reivindicando a relevância do ponto de vista sociológico sobre tal fenômeno tido como exclusivo aos economistas, e em Schumpeter (1991), segundo o qual: "As finanças são um dos melhores pontos de entrada para estudar os mecanismos sociais.” (idem, p.101 apud Grün, 2004) .

O também interdisciplinar enfoque do isomorfismo coercitivo, mimético e normativo do neo-institucionalismo sociológico (POWELL; DiMAGGIO, 1991) fornecerá a base teórica para a análise dos processos interpretativos através dos quais os atores compreendem o comportamento daqueles que os cercam e reformulam os modelos cognitivos que guiam suas ações, seus comportamentos e decisões, todos largamente influenciados e constrangidos pelo comportamento/ação/decisão "do outro". Tal processo de mimetismo pode acontecer sem que nenhum dos agentes envolvidos se dê conta de que estão influenciando o (ou sendo influenciado pelo) comportamento do(s) outro(s) agentes, e quanto menos percebida for essa influência, ou, quanto mais "naturalizada", ela se fizer sentir, mais poderosa e duradoura também se tornará. 
(DOUGLAS, 1998)

Esse gênero de análise irá mostrar, entre outros, como as organizações influenciadas / constrangidas pela lógica financeira têm adotado sistemas para automação da produção do tipo ERPs, menos por sua eficiência técnica, e mais pela percepção de que essa decisão a legitima perante um ambiente institucional em que negócios bilionários miram em direção a usinas cuja gestão esteja "mais profissionalizada", para usar um termo, atualmente em voga, para tratar do setor. A incerteza que permeia as organizações, também, as impele/encoraja à imitação de outras organizações tidas como legítimas ou bem-sucedidas pelo senso comum. Assim decisões tomadas com base nos movimentos das fontes inspiradoras são legitimadas, sendo preferível não ganhar tanto (nem perder tanto) por agir segundo a "manada" do que correr o risco de ganhar muito (ou perder tudo) ao tomar uma decisão divergente.

Outra atuação do mecanismo mimético sobre as usinas pode ser percebida na divulgação da adoção de programas ou certificações ambientais, de responsabilidade social, códigos de ética, por usinas que, agora, empenham-se num trabalho de reconstrução da imagem do setor, lócus de contenciosos envolvendo desde problemas sucessórios até disputas fiscais, trabalhistas e ambientais passando por falta de transparência e contabilidade confiável. O setor, célebre por sua estrutura de controle familiar, mostra-se disposto a dançar conforme a música da "empresa responsável”, mesma apreciada pelos investidores, buscando para isso, auxílio das consultorias, visando a "profissionalização de sua gestão" a toque de caixa, principalmente através de reestruturação financeira, através do emprego da engenharia financeira para a criação de valor; reestruturação produtiva, através da reengenharia, do downsizing e do emprego do SAP; e reestruturação administrativa, com a governança corporativa e seu discurso sobre sustentabilidade.

Ao mesmo tempo, os atores industriais do setor sucroalcooleiro passam a compartilhar com atores do espaço financeiro os controles, não só "sobre a empresa", mas também sobre o que "é a empresa", ao balizarem as decisões sobre o destino das usinas e imporem subliminarmente sua definição sobre o tema, implícita nos contornos impressos pela nova gestão, que refletirá, em grande medida, sua visão de mundo (corporativo, ou das finanças) concorrente à visão de mundo do usineiro e que oriundo da elite agrária através dos subsídios do Proálcool, a partir da década de 70, logrou conseguir firmar o Brasil num patamar industrial entre os maiores e melhores produtores de açúcar e álcool do mundo, potencializando o conflito entre esses atores. Enquanto para os primeiros, a empresa não passa de um feixe de contratos, para os atores do espaço agrário-industrial do setor sucroalcooleiro, seus empreendimentos ocupam um lugar entre as conquistas de seus antepassados e a geração de riqueza garantida às gerações futuras.

Em função disso, o estudo social das finanças proposto, neste, pode conduzir-nos a uma aproximação do que Fligstein (1998) chamou de "campo organizacional”. Segundo o autor, a interação social se dá em contextos que ele chamou de campos onde atores com diferentes capacidades organizacionais regulam seu comportamento em função dos outros atores e, empregam suas habilidades sociais dependendo de suas posições no campo e dos movimentos 
de outros grupos no campo. A construção de um campo organizacional ocorre quando grupos de atores sociais confrontam-se em algum tipo de interação social contenciosa, pela disputa por recursos escassos entre grupos com diferentes graus de poder ou quando as regras existentes não servem mais aos interesses do grupo existente. Os campos podem entrar em crise com o resultado de mudanças que ocorrem fora destes e, freqüentemente, estas são vistas como oportunidades para um grupo de atores concorrentes visando à institucionalização de uma nova ordem.

Para uma análise inicial do setor foram adotados os referenciais teóricos da abordagem político-cultural de Fligstein (1998) para abordar-se a dinâmica de determinados mercados, analisando, como eles se constituem e se mantêm estáveis e quais as forças que transformam esses espaços; o pressuposto da Racionalidade Limitada de Simon (1991) para entender a natureza da tomada de decisão dos gerentes e diretores; e as vertentes econômicas e sociológicas da Teoria Institucional, para analisar se, e em que medida, os mecanismos de compensação salarial sugeridos pela Teoria da Agência (Fama \& Jensen, 1983) são suficientemente eficazes para sobrepor-se aos constrangimentos sociais impostos à ação gerencial pelo isomorfismo institucional.

\section{RESULTADOS INICIAIS OBTIDOS}

Este trabalho se insere num projeto franco-brasileiro mais amplo intitulado "Changement de Proprieté dês Unités de Production au Brésil" firmado entre pesquisadores franceses e brasileiros presentes ao Seminário Temático Centralidade e Fronteiras das Empresas no Século XXI, organizado pelos pesquisadores do Núcleo de Sociologia Econômica e das Finanças (NESEFI/UFSCar) em novembro de 2007 na Universidade Federal de São Carlos. Dessa forma, os resultados iniciais apresentados, aqui, representam a primeira coleta de dados e têm o intuito de alavancar e reorientar nossas intenções de pesquisa.

Para a compreensão do processo de institucionalização dessa nova ordem de "financeirização do setor sucroalcooleiro" mencionada acima, faz-se necessário entender a constituição do mercado de bioenergia e os principais núcleos de influência que moldam o setor. Nesse sentido, um primeiro exercício para passar pelo mapeamento inicial dos movimentos de fusões, aquisições e fundos de participações, nacionais e estrangeiros, para dessa forma, construirmos um espaço aderente aos enfoques citados da Sociologia das Finanças e do Isomorfismo, e que, também, forneça elementos internos sobre a atuação e a representação social do mercado de bioenergia, além de precisar a extensão da participação de capital estrangeiro no fenômeno (da financeirização). A dificuldade de acesso a informações relativas às negociações, muitas sigilosas, em curso é auto-explicativa, mas o exame da construção do espaço do mercado de bioenergia junto à imprensa de negócios possibilitou que esse exercício fosse iniciado e apresentado nas tabelas a seguir:

Nucleus, v. 5. n. 1 , abr. 2008 
Tabela 1: Novos investidores no Setor Sucroalcooleiro Nacional e seus Investimentos

(Continua)

\begin{tabular}{|c|c|c|}
\hline Grupo & Principais Investidores & Investimentos \\
\hline $\begin{array}{l}\text { Brenco (planos } \\
\text { de abertura de } \\
\text { capital para } \\
2008-2009 \text { e } 10 \\
\text { usinas até 2015) }\end{array}$ & $\begin{array}{l}\text { Henri Phillipe Reichstul (CEO) } \\
\text { Vinod Khosla } \\
\text { James Wolfensohn } \\
\text { Steve Case } \\
\text { Bill Clinton } \\
\text { David Zylbersztajn } \\
\text { Ron Burkle } \\
\text { Khosla Ventures } \\
\text { Tarpon All Equities Fund } \\
\text { Perkins Caufield \& Byers } \\
\text { Tarpon Investiments } \\
\text { Semco } \\
\text { Ashmore Energy Int. }\end{array}$ & $\begin{array}{l}8 \text { Projetos Greenfield para } \\
\text { álcool a partir de } 2010 \text { "Usinas } \\
\text { da Arte": } \\
1 \text { Alto Taquari (MT) } \\
2 \text { Paranaíba (MS) } \\
1 \text { Costa Rica (MS) } \\
2 \text { Mineiros (GO) } \\
1 \text { Perolândia (GO) } \\
1 \text { Itajá (GO) } \\
\text { Outros no Caribe } \\
\text { Alcoodutos (Parceria Petrobrás) }\end{array}$ \\
\hline $\begin{array}{l}\text { ETH Bioenergia } \\
\text { (abertura de } \\
\text { capital e } 10 \\
\text { usinas até 2015) }\end{array}$ & $\begin{array}{l}\text { Clayton Higino de Miranda (CEO) } \\
\text { Odebrecht } \\
\text { Eduardo Pereira de Carvalho } \\
\text { Sojitz Corporation } \\
\text { Alexandre Cândido de Pádua } \\
\text { (controlador ACP Agropecuária, sócio } \\
\text { Reebok Fitness) }\end{array}$ & $\begin{array}{l}\text { Usina Alcídia (SP) } \\
8 \text { Projetos Greenfield: } \\
2 \text { em Nova Alvorada do Sul } \\
\text { (MS) } \\
1 \text { em Nova Andradina (MS) } \\
1 \text { em Itarumã (GO) } \\
2 \text { em Caçu (GO) } \\
1 \text { no Pontal (SP) } \\
1 \text { em Angola (AFR) } \\
\text { Alcoodutos e Terminais } \\
\text { portuários }\end{array}$ \\
\hline $\begin{array}{l}\text { Infinity } \\
\text { Energy (capital } \\
\text { aberto em } 2006 \\
\text { na Bolsa de } \\
\text { Londres) }\end{array}$ & $\begin{array}{l}\text { Sérgio Thompson Flores (CEO) } \\
\text { Kidd and Company } \\
\text { Evergreen } \\
\text { Merril Linch } \\
\text { Andrew Lipman } \\
\text { William Kidd } \\
\text { Martin Escobari } \\
\text { Jean Lesur } \\
\text { Alberto Tepedino } \\
\text { Stuart Maron } \\
\text { Paulo Vasconcellos } \\
\text { Rodrigo Aguiar }\end{array}$ & $\begin{array}{l}\text { Usina Alcana (MG) } \\
\text { Usina Cridasa (ES) } \\
\text { Usinavi (MS) } \\
\text { Usina Disa (ES) } \\
\text { Usina Coopernavi } \\
\text { Usina Ibirálcool (BA) } \\
\text { Usina Cepar (MG) } \\
\text { Usina Agromar (RN) }\end{array}$ \\
\hline
\end{tabular}


Tabela 1: Novos investidores no Setor Sucroalcooleiro Nacional e seus Investimentos

\begin{tabular}{l|l|l}
\hline & & Usina Luciânia (MG) \\
& & Usina Crescimal (SP) \\
Usina São Carlos (SP) \\
Usina Estivas (RN) \\
Giasa (PB) \\
Usina Passa Tempo (MS) \\
& Robert Louis Dreyfus (Presidente) & Usina Maracaju (MS) \\
& Kenneth C. Geld (CEO) & Usina Rio Brilhante (MS) \\
Grupo Coinbra- & Grupo Tavares de Mello & 1 Greenfield: Usina Esmeralda \\
Dreyfus & LDC Commodities & MS) \\
& Wafic Said & 2terminaisportuários(Paranaguá \\
& & e Santos) \\
\hline A d e c o & Mariano Bosch Jr. (CEO) & Usina Monte Alegre (MG) \\
Agropecuária & George Soros & \\
\hline
\end{tabular}

Tabela 2: Novos investidores no Setor Sucroalcooleiro Nacional e seus Investimentos (cont.)

\begin{tabular}{l|l}
\hline INVESTIDOR & INVESTIMENTO \\
\hline & 2 projetos Greenfields: \\
1 usina em Nova Andradina (MS) \\
1 usina em Batayporã (MS)
\end{tabular}


Tabela 2: Novos investidores no Setor Sucroalcooleiro Nacional e seus Investimentos

(Conclusão)

\begin{tabular}{l|l}
\hline Grupo Ultra & 1 Biorrefinaria em Comendador Gomes \\
\hline Grupo Bertin & 2 usinas de álcool em Capinópolis (MG) \\
\hline Darby-Stratus & Alcooduto \\
(FIP para infrestrutura) & Tancagem de produtos em terminais portuários \\
\hline HBK Group (EUA) & US\$ 1 bilhão \\
\hline Südzucker (ALE) & Trading HOSA (Hottlet South América) \\
\hline Mitsui (JAP) & 40 usinas de etanol até 2011 (com Petrobrás) \\
\hline Mitsubishi (JAP) & $\begin{array}{l}\text { Construção em sociedade com o Grupo São } \\
\text { Martinho da Usina Boa Vista (GO) }\end{array}$ \\
\hline Petrobrás & 3 usinas a serem concluídas em 2007 \\
\hline Marubeni (JAP) & Alcooduto ligando Centro-Oeste ao Sudeste \\
\hline Agrenco (FRA) & Participação Societária na Agrenco \\
\hline Globex (EUA) & Trading \\
\hline & US\$ 50 milhões em planta de etanol \\
\hline
\end{tabular}

Tabela 3: Grupos Nacionais com Capital Aberto em Bolsas de Valores (Bovespa e NYSE)

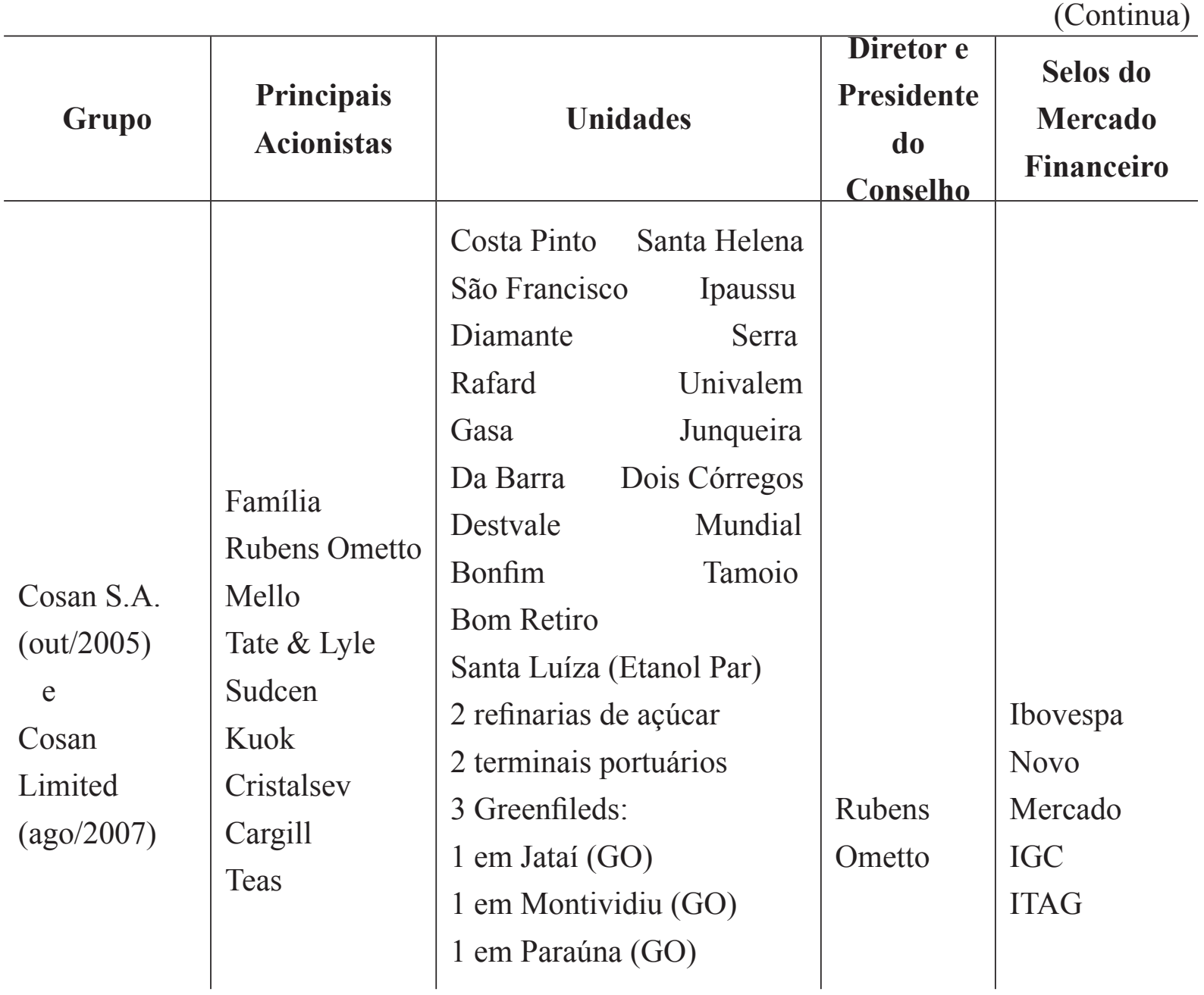


Tabela 3: Grupos Nacionais com Capital Aberto em Bolsas de Valores (Bovespa e NYSE)

\begin{tabular}{|c|c|c|c|c|}
\hline $\begin{array}{l}\text { São } \\
\text { Martinho SA } \\
(\text { fev/2007) }\end{array}$ & $\begin{array}{l}\text { Família João } \\
\text { Ometto }\end{array}$ & $\begin{array}{l}\text { Iracema } \\
\text { Santa Luzia (Etanol Par) } \\
\text { São Martinho } \\
\text { Boa Vista (sociedade com a } \\
\text { Mitsubishi Co. em GO) }\end{array}$ & $\begin{array}{l}\text { João } \\
\text { Ometto }\end{array}$ & $\begin{array}{l}\text { Novo } \\
\text { Mercado } \\
\text { IGC } \\
\text { ITAG }\end{array}$ \\
\hline $\begin{array}{l}\text { Nova } \\
\text { América } \\
\text { (maio/2007) }\end{array}$ & $\begin{array}{l}\text { Família } \\
\text { Rezende de } \\
\text { Barbosa }\end{array}$ & $\begin{array}{l}\text { Piedade } \\
\text { Sertãozinho } \\
\text { Nova América } \\
\text { Macaraí } \\
\text { Paraguaçu Paulista } \\
\text { Destilaria Paraguaçu } \\
\text { Terminal Portuário em } \\
\text { Santos }\end{array}$ & $\begin{array}{l}\text { Roberto } \\
\text { Rezende de } \\
\text { Barbosa }\end{array}$ & Nada consta \\
\hline $\begin{array}{l}\text { Guarani } \\
\text { (set/2007) }\end{array}$ & $\begin{array}{l}\text { Família } \\
\text { Phillipe Duval } \\
\text { Tereos } \\
\text { FBA }\end{array}$ & $\begin{array}{l}\text { Guarani } \\
\text { Andrade } \\
\text { Tanabi } \\
\text { São José } \\
\text { Cardoso } \\
\text { Cruz Alta } \\
\text { Severínia } \\
\text { Moçambique }\end{array}$ & $\begin{array}{l}\text { Jacyr Costa } \\
\text { Filho } \\
\text { (Prêmio } \\
\text { Mastercana } \\
\text { de } \\
\text { Executivo } \\
\text { do Ano }\end{array}$ & $\begin{array}{l}\text { Novo } \\
\text { Mercado }\end{array}$ \\
\hline
\end{tabular}


Tabela 4: Governança Corporativa: Responsabilidade Social, ERPs e Consultorias

\begin{tabular}{|c|c|c|c|c|c|}
\hline \multicolumn{6}{|c|}{ (Continua) } \\
\hline $\begin{array}{c}\text { Grupo 1: } \\
\text { Gestão Familiar }\end{array}$ & $\begin{array}{l}\text { Famílias } \\
\text { Gestoras }\end{array}$ & $\begin{array}{c}\text { ERP / } \\
\text { Banco de } \\
\text { Dados }\end{array}$ & Consultoria & $\begin{array}{c}\text { Responsabili- } \\
\text { dade Social }\end{array}$ & $\begin{array}{c}\text { Ba- } \\
\text { lanço } \\
\text { Social }\end{array}$ \\
\hline $\begin{array}{l}\text { Grupo Balbo } \\
\text { - Usina Santo } \\
\text { Antônio } \\
\text { - Usina São } \\
\text { Francisco }\end{array}$ & Balbo & $\begin{array}{l}\text { SSTI } \\
\text { Datasul / } \\
\text { SQL Oracle }\end{array}$ & Microsiga & $\begin{array}{l}\text { Biodiversidade } \\
\text { Orgânicos } \\
\text { Polímero de } \\
\text { Açúcar }\end{array}$ & Não \\
\hline $\begin{array}{l}\text { Grupo Pedra } \\
\text { Agroindustrial } \\
\text { - Usina da Pedra } \\
\text { - Usina Buriti } \\
\text { - Usina Ibirá }\end{array}$ & $\begin{array}{l}\text { Biagi } \\
\text { Velho }\end{array}$ & $\begin{array}{l}\text { Equipe } \\
\text { Interna de } \\
\text { TI / Oracle }\end{array}$ & Interna & $\begin{array}{l}\text { Sim } \\
\text { Polímero de } \\
\text { Açúcar (em } \\
\text { parceria com } \\
\text { Crystalsev e } \\
\text { Balbo) }\end{array}$ & Não \\
\hline $\begin{array}{l}\text { Grupo Santa Adélia } \\
\text { - Usina Santa } \\
\text { Adélia } \\
\text { - Usina Interlagos }\end{array}$ & Bellodi & $\begin{array}{l}\text { Datasul / } \\
\text { Oracle }\end{array}$ & $\begin{array}{l}\text { Eba } \\
\text { Consultoria }\end{array}$ & Não & Não \\
\hline $\begin{array}{l}\text { Grupo João Pessoa } \\
\text { - Usina Benálcool } \\
\text { - Usina CBAA }\end{array}$ & $\begin{array}{l}\text { Toninho } \\
\text { Tonielo }\end{array}$ & $\begin{array}{l}\text { Logix / } \\
\text { Oracle }\end{array}$ & Logocenter & Sim & Não \\
\hline Usina São João & $\begin{array}{l}\text { Ainda não } \\
\text { identificada }\end{array}$ & $\begin{array}{l}\text { SoftFácil / } \\
\text { Oracle }\end{array}$ & CNBR & $\operatorname{Sim}$ & Sim \\
\hline Usina Santa Isabel & $\begin{array}{l}\text { Ainda não } \\
\text { identificada }\end{array}$ & $\begin{array}{l}\text { CHB / SQL } \\
\text { Server }\end{array}$ & Interna & Não & Não \\
\hline Usina Colorado & $\begin{array}{l}\text { Ribeiro de } \\
\text { Mendonça }\end{array}$ & $\begin{array}{l}\text { SGAgrícola } \\
\text { Oracle }\end{array}$ & Interna & $\begin{array}{l}\text { Sim, GC em } \\
\text { livro } \\
\text { Colheita } \\
\text { mecanizada }\end{array}$ & Não \\
\hline $\begin{array}{l}\text { Grupo Alta } \\
\text { Mogiana S /A } \\
\text { - Usina Alta } \\
\text { Floresta } \\
\text { - Usina Alto } \\
\text { Alegre }\end{array}$ & $\begin{array}{l}\text { Lincoln } \\
\text { Junqueira }\end{array}$ & $\begin{array}{l}\text { SGEAM / } \\
\text { Oracle }\end{array}$ & Interna & Sim & Sim \\
\hline
\end{tabular}


Tabela 4: Governança Corporativa: Responsabilidade Social, ERPs e Consultorias

(Conclusão)

Grupo Santa Elisa

Vale $\mathrm{S} / \mathrm{A}$ :

. Usina Vale do

Rosário

. Cia.Energ.Santa

Elisa

. Usina MB

. Usina Jardest

. Usina Continental

. Banco Goldman

Sachs

. Trading Cristalsev

6 Greenfields

4 Greenfields com

CNAA:

- Separ S/A

- FIP Açúcar e

Álcool:

- Riverstone

Biagi Novo e Junqueira Franco SGI/ (Honra ao Mérito Ingres $\mathrm{CA}$ Interna 2007) e Anselmo Lopes Rodrigues

- D.A. Capital

- Discovery

- Global Foods

- Goldman Sachs (CEO )

Sim (Empresa do Ano 2007 pela Revista Exame) 
Tabela 5: Governança Corporativa: Responsabilidade Social, ERPs e Consultorias

\begin{tabular}{l|l|l|l|l|l}
\hline $\begin{array}{l}\text { Grupo 2: } \\
\text { Gestão Profis- } \\
\text { sional }\end{array}$ & ERP & $\begin{array}{l}\text { Banco de } \\
\text { Dados }\end{array}$ & Consultoria & $\begin{array}{l}\text { Responsabilida- } \\
\text { de Social }\end{array}$ & Balanço Social \\
\hline Cosan & $\begin{array}{l}\text { Datasul } \\
\text { Logix } \\
\text { SAP }\end{array}$ & Oracle & $\begin{array}{l}\text { Bearing } \\
\text { Point }\end{array}$ & Sim & Não \\
\hline São Martinho & $\begin{array}{l}\text { Datasul } \\
\text { SAP }\end{array}$ & Oracle & SAP & Sim & Não \\
\hline Nova América & Datasul & Oracle & Pirâmide & Sim & Sim \\
\hline Guarani & $\begin{array}{l}\text { TI } \\
\text { interna }\end{array}$ & Oracle & Interna & Sim & Sim \\
\hline
\end{tabular}

Tabela 6: Governança Corporativa: Responsabilidade Social, ERPs e Consultorias

\begin{tabular}{|c|c|c|c|c|c|}
\hline $\begin{array}{l}\text { Grupo 3: } \\
\text { Entrantes }\end{array}$ & ERP & $\begin{array}{l}\text { Banco de } \\
\text { Dados }\end{array}$ & $\begin{array}{l}\text { Consulto- } \\
\text { ria }\end{array}$ & $\begin{array}{l}\text { Responsabilida- } \\
\text { de Social }\end{array}$ & Balanço Social \\
\hline Adeco & $\begin{array}{l}\text { EMS } \\
204\end{array}$ & Progress & Datasul & Não & Não \\
\hline Agrenco & Datasul & Progress & Datasul & Patrocínios & $\begin{array}{l}\text { Não, mas } \\
\text { busca o selo } \\
\text { Combustível } \\
\text { Social do Gov. } \\
\text { Federal }\end{array}$ \\
\hline Noble Group & Datasul & Progress & SAP & $\begin{array}{l}\text { Investimentos } \\
\text { Sociais (Petribú) }\end{array}$ & Não \\
\hline $\begin{array}{l}\text { Infinity Bio- } \\
\text { Energy }\end{array}$ & $\begin{array}{l}\text { Sapiens } \\
\text { VetoRH } \\
\text { Datasul }\end{array}$ & Oracle & Datasul & $\begin{array}{l}\text { Refeições } \\
\text { quentes } \\
\text { Transporte } \\
\text { Alojamentos } \\
\text { Comida para } \\
\text { índios }\end{array}$ & Não \\
\hline $\begin{array}{l}\text { Coinbra- } \\
\text { Dreyfus }\end{array}$ & $\begin{array}{l}\text { SAP } \\
\text { Datasul }\end{array}$ & Oracle & SAP & $\begin{array}{l}\text { Compromisso } \\
\text { social }\end{array}$ & Não \\
\hline Pátria Energia & Protheus & $\begin{array}{l}\text { SQL } \\
2005\end{array}$ & Microsiga & Não & Não \\
\hline Brenco & \multicolumn{5}{|c|}{$\begin{array}{l}\text { Projetos Greenfield com sustentabilidade e } 100 \% \text { de colheita mecanizada } \\
\text { Projetos MDL para venda de Créditos de Carbono } \\
\text { Governança Corporativa e Código de Ética em construção }\end{array}$} \\
\hline $\begin{array}{l}\text { ETH } \\
\text { Bioenergia }\end{array}$ & \multicolumn{5}{|c|}{ Somente anunciada no site da Odebrecht, porém sem informações } \\
\hline
\end{tabular}




\section{CONSIDERAÇÕES FINAIS}

Os resultados iniciais apontados pela pesquisa junto à imprensa de negócios e profissionais do setor mostrou que empresas de capital fechado do setor sucroalcooleiro têm buscado legitimidade para atuarem no novo ambiente institucional em construção, o mercado de bioenergia, aderindo às inovações no setor e seguindo os passos das empresas de capital aberto (divulgando informações como balanços e outras demonstrações financeiras, balaço social, governança corporativa etc).

Assim, pôde ser observado que o setor, famoso por sua estrutura de controle familiar, mostra-se disposto a dançar conforme a música da "empresa responsável / sustentável / transparente / justa / viável", sendo grande a preocupação com a profissionalização da gestão, principalmente, através da adoção de sistemas de gestão, ERPs (MENDONÇA; SALTORATO, 2007), reengenharias e contratação de consultorias.

É maciça, a presença de investidores estrangeiros no setor, seja por meio de participações em negócios estabelecidos, ou através de projetos greenfields. A agenda de profissionalização da gestão, imposta pela Única e pelos novos atores ao forjarem um novo ambiente institucional para o setor, também faz parte de suas preocupações para as usinas adquiridas (porém nos projetos greenfield. Isso não chega a ser uma preocupação, já que nascem longe da interferência do controle familiar, claramente, o alvo da agenda da profissionalização da gestão). Porém a divulgação de ações sociais por parte dos investidores estrangeiros difere em grau e natureza daquelas alardeadas pelos investidores nacionais, como por exemplo, podemos citar a Infinity BioEnergy que chama de Responsabilidade Social as refeições quentes servidas aos índios (muito mais, uma tentativa de conquistá-los e evitar conflitos no curto prazo, durante sua instalação, que uma ação de longo prazo), priorizando, sim, a "sustentabilidade econômica" desses empreendimentos. Num outro exemplo, o do Grupo Brenco, podemos ainda observar a plasticidade em torno do conceito da Responsabilidade Social entre os investidores estrangeiros e os grupos nacionais; enquanto os primeiros referem-se à implantação da colheita 100\% mecanizada como uma ação socialmente responsável, para os grupos nacionais, isso significaria a demissão em massa de trabalhadores e historicamente associada a uma irresponsabilidade social do setor. Tamanha plasticidade, porém, antes de impedir a apropriação do termo por um número cada vez maior de organizações, pode sim, contribuir para sua difusão indiscriminada.

A atuação de uma nova classe de investidores na profissionalização da gestão faz-se direta e intensamente, sendo a revisão de metas e a troca de executivos as principais (e iniciais) providências tomadas pelos gestores de fundos de private equity nos primeiros cem dias (Value Partners e da FGV, 2007), sendo, porém, ainda, maciça, a presença familiar na gestão das usinas no Estado de São Paulo. Muitos usineiros têm agido com o intuito de atrair novos investidores, mas nem de longe, pensam em vender conforme declarou Cícero Junqueira (proprietário da Santa Elisa Vale, antiga Vale do Rosário) "Vender? Vender para que?!?" ou abrir mão do controle sobre seus negócios, conforme pôde ser visto no episódio da abertura de capital da 
Cosan na Bolsa de Valores de Nova York, com a criação da Cosan Limited, quando Rubens Ometto supervalorizou suas ações, em detrimento dos acionistas minoritários, exatamente aqueles supostamente amparados pelos preceitos da Governança Corporativa, tão largamente propagandeada pelo grupo.

Aproximação entre o setor industrial da produção de açúcar e álcool e do espaço financeiro, sugere uma Dinâmica Financista em curso, promotora de uma "Guerra Cultural" (GRÜN, 1999), na qual visões de mundo potencialmente opostas (às quais podem ser associados modelos de empresa e de gestão particulares) (GRÜN, 1999), convivem em aparente "harmonia" entre si, visando, tanto construir um novo espaço de atuação para todos, como fortalecer suas posições nele, através da definição de regras e valores para seu funcionamento que aos poucos vão sendo definidos pelos atores com maiores (e melhores) capitais presentes no novo espaço em construção, no caso o mercado de bioenergia. À medida que esta construção vai se consolidando e se estabelece certa estabilidade para os atores desempenharem seus papéis, tal "harmonia" vai sendo desafiada à medida que as regras vigentes já não sirvam mais aos interesses dos atores mais influentes ali presentes, interessados em redefini-las, através de conflitos explícitos (se preciso for), incipientes no início, quando à cooperação entre os novos players se faz mais decisiva na legitimação e estabelecimento do novo espaço.

Por mais que ambas as visões de mundo, a industrial e a financeira, colidam-se, a primeira silencia-se e é renaturalizada em meio ao discurso da sustentabilidade, enquanto a segunda, não comemora explicitamente seu poderio, apesar de exercê-lo institucionalmente;

Dessa forma, representantes da elite agrária, que através do Proálcool, lograram êxito ao firmar o Brasil num patamar industrial entre os maiores e melhores produtores de açúcar e álcool do mundo, afastam (aos poucos) a participação familiar na gestão e se submetem, agora, à visão de mundo dos atores do espaço financeiro, embalados numa dinâmica financista que impõe uma dominação cultural, além da financeira, promovendo uma "guerra cultural" (GRÜN, 1999), onde ambos os lados saem "vencedores", enquanto para ambos, aumento de receita for suficiente para significar "vitória". Porém, se para um desses lados, a "vitória" estiver também associada a outros ganhos, como aumento de poder, só um deles (em cada senóide da dinâmica) poderá lograr-se "vitorioso... Foi dentro desse contexto, que os usineiros, por um lado, subliminarmente cunhados como "amadores" pelos promotores da construção do mercado de bioenergia; mas por outro (lado), experientes, e com fôlego suficiente para resistir às crises do setor não se viram tão prejudicados assim, com as perdas enfrentadas no trimestre final de 2007, que, afugentou parte dos novos (e, ingênuos, em suas avaliações) investidores que "caíram de pára-quedas" (em suas palavras) no setor querendo "ensinar o Pai Nosso aos vigários" (também em suas palavras), mostrando aos sobreviventes que eles "não sabem da missa, a metade"... 


\section{REFERÊNCIAS}

BALTHAZAR, R. Bill Clinton reforça o time de investidores da Brenco. Valor Econômico. 4 jul. 2007.

DOUGLAS, M. (1998). Como as instituições pensam. São Paulo: EDUSP, 1998.

FAMA, E.; JENSEN, M. Separation of Ownership and Control Agency Problems and Residual Claims. Journal of Law and Economics, v.26, pp.327-350, 1983.

FLIGSTEIN, N. Fields, power and social skill: a critical analysis of the new institutionalisms. Department of Sociology. University of California. Berkley, Ca., 1998.

GRÜN, R.. Modelos de mundo, modelos de empresa: sobre algumas características culturais da nova ordem econômica e da resistência a ela. Revista Brasileira de Ciências Sociais, São Paulo, v. 14, n.41, p.121-140, 1999.

GRÜN, R. A evolução recente do espaço financeiro no Brasil e alguns reflexos na cena política. Dados. Rio de Janeiro, v.47, n.1, 2004.

MENDONÇA, E.; SALTORATO, P. Profissionalização da gestão no setor sucroalcooleiro: a introdução do ERP na Cosan $\mathbf{S} /{ }^{\text {a }}$. In: SEMINÁRIO TEMÁTICO CENTRALIDADE E FRONTEIRAS DAS EMPRESAS NO SÉCULO XXI, 1. São Carlos, UFSCar, de 19 a 21 de novembro de 2007.

MUNDO NETO, M.; SALTORATO, P. A dinâmica financista no setor sucroalcooleiro, ou quando a transparência vira moda. In: SEMINÁRIO TEMÁTICO CENTRALIDADE E FRONTEIRAS DAS EMPRESAS NO SÉCULO XXI, 1. São Carlos, UFSCar, de 19 a 21 de novembro de 2007.

POLANYI, K. [1944], The Great Transformation: The Political and Economic Origins of our Time, Beacon Press, Boston, 2001.

POWELL, W. W.; DIMAGGIO P.J. The Iron cage revisited: institutional isomorphism and collective rationality in organizational fields. Chicago: University of Chicago Press, 1991.

REGALADO,A.; FAN, G. Controle familiar freia investida estrangeira no álcool brasileiro. Valor Econômico. 10 set. 2007.

SCARAMUZZO, M. Brenco adquire usinas de última geração da Dedini. Valor Econômico. 17 set. 2007.

SCARAMUZZO, M. Südzucker investe em trading no país e mira aquisições. Valor Econômico. 31 jul. 2007. 
SCARAMUZZO, M.; VALENTI, G. Álcool ganha força na Bovespa com estréias. Valor Econômico. 17 set. 2007.

SCHUMPETER, J. A. The economics and sociology of capitalism. Nova Jersey: Princeton University Press, 1991.

SIMON, H.A. Organization and Markets. Journal of Economic Perspectives. v.5, n.2, p. 2544.

VALUE Partners Brasil. Fundos de private equity monitoram gestão da empresa. FGVEAESP, 2006.

ZANATTA, M. Etanol, febre movida a subsídios nos EUA. Valor Econômico. 06 nov. 2007. 